(C) Dereito Vol.26, n02:29-42 (Xullo-Decembro, 2017) • ISSN 1132-9947

\title{
LA OBLIGACIÓN DE INFORMAR Y SU COMPATIBILIDAD CON EL DERECHO A LA LIBERTAD DE EXPRESIÓN
}

The obligation to disclose information and its compatibility with the right to freedom of expression

DOI: http://dx.doi.org/10.15304/dereito.26.2.3725

\author{
Elena SALGado AndRÉ \\ Universidad de Vigo \\ elenasalgadoandre@hotmail.com
}

\section{Resumen}

Como es sabido, la publicidad tiene una doble vertiente -informativa y persuasiva- y en cada anuncio puede prevalecer indistintamente una u otra. Sin embargo, con el paso de los años se adivina una tendencia a reforzar la dimensión informativa debido a la convivencia de una serie de normas comunitarias y estatales que regulan el engaño por omisión y establecen obligaciones específicas de información en determinados sectores. Precisamente, la existencia de tales normas nos conduce a un problema de compatibilidad con el derecho a la libertad de expresión.

Tras analizar el origen de la tendencia apuntada y la postura de diferentes Tribunales acerca del reconocimiento de protección constitucional a los mensajes de naturaleza publicitaria, se comprueba si la exigencia de un deber de información al anunciante -como límite a la libertad de expresión- puede considerarse una injerencia lícita en el ámbito de protección del citado derecho.

Palabras clave: libertad de expresión, publicidad, omisiones engañosas, obligación de informar

\section{Abstract}

As it is known, advertising has a double dimension -informational and persuasive- and each advertisement one or the other may prevail. However, over the years, a tendency to strengthen the informational dimension may be seen due to the coexistence of a number of community and national laws relating to misleading omissions and requiring disclosure information in certain sectors. Indeed, the existence of such laws leads to a problem of compatibility with the right to freedom of expression.

After analyzing the origin of the targeted trend and the position of different Courts on the recognition of constitutional protection to commercial speech, it is checked whether impose an obligation to disclose information, as limit to freedom of expression, may be considered a lawful measure in the field of protection of that right.

Keywords: freedom of expression, advertising, misleading omissions, obligation to disclose information.

Recibido: 15/11/2016. Aceptado: 19/01/2017. 


\section{SUMARIO}

1. EL REFORZAMIENTO DE LA VERTIENTE INFORMATIVA DE LA PUBLICIDAD.- 2. PUBLICIDAD COMERCIAL Y LIBERTAD DE EXPRESIÓN.2.1. Introducción.- 2.2. El amparo constitucional de la publicidad comercial en el Derecho norteamericano.- 2.3. El amparo constitucional de la publicidad comercial en la jurisprudencia del Tribunal Europeo de Derechos Humanos.- 2.4. El amparo constitucional de la publicidad comercial en la jurisprudencia del Tribunal Supremo.- 3. OMISIONES ENGAÑOSAS Y LIBERTAD DE EXPRESIÓN.- 3.1. Omisiones engañosas.3.2. Leyes que imponen obligaciones específicas de información.- 4. BIBLIOGRAFÍA.

\section{SUMMARY}

1.THE PROCESS OF STREGTHENING OF THE INFORMATION ADVERTISING.- 2. COMMERCIAL SPEECH AND FREEDOM OF EXPRESSION. 2.1. Introduction.- 2.2. The constitutional protection of commercial speech in American Law.- 2.3. The constitutional protection of commercial speech in the jurisprudence of the European Court of Human Rights.- 2.4. The constitutional protection of commercial speech in the jurisprudence of the Supreme Court.- 3. MISLEADING OMISSIONS AND FREEDOM OF EXPRESSION.- 3.1. Misleading omissions.- 3.2. Laws that impose an obligation to disclose specific information.- 4. BIBLIOGRAPHY.

\section{EL REFORZAMIENTO DE LA VERTIENTE INFORMATIVA DE LA PUBLICIDAD}

Al delimitar las funciones de la actividad publicitaria, la primera cuestión que debe abordarse es el concepto de publicidad. En España, el art. 2 de la Ley 34/1988, de 11 de noviembre, General de Publicidad (LGP) define la publicidad como "toda forma de comunicación realizada por una persona física o jurídica, pública o privada, en el ejercicio de una actividad comercial, industrial, artesanal o profesional, con el fin de promover de forma directa o indirecta la contratación de bienes muebles o inmuebles, servicios, derechos y obligaciones" ${ }^{1}$.

La somera lectura del precepto transcrito pone de manifiesto que la publicidad engloba todas aquellas actividades de comunicación encaminadas a promover la contratación de los productos o servicios de una empresa. De este modo, a través de la publicidad el empresario da a conocer al público las características de sus mercancías, al tiempo que trata de convencer a los consumidores para que las adquieran. Ésta es la denominada doble vertiente informativa y persuasiva de la publicidad,

\footnotetext{
${ }^{1}$ Sobre el concepto de publicidad en el Derecho español existen numerosos trabajos. A título de ejemplo, vid. A. TATO PLAZA, "La publicidad ilícita en la jurisprudencia y en la doctrina del Jurado de la Publicidad, Autocontrol, núm. 27, enero (1999), pp. 3-4 (versión consultada en www.autocontrol.es) y E. GALÁN CORONA, "Análisis de la jurisprudencia publicitaria (parte I)", Autocontrol, núm. 145, octubre (2009), pp. 10-11.
} 
aunque lógicamente en los diferentes anuncios puede prevalecer una u otra $^{2}$.

No obstante, en los últimos tiempos han cambiado las tornas y parece existir una tendencia favorable a reforzar el perfil informativo de la publicidad. Esta tendencia se refleja en el plano legislativo, tanto comunitario como estatal, aunque su origen habrá que buscarlo en Derecho norteamericano cuando el legislador consagró una obligación positiva de informar con el propósito de proteger los intereses de los consumidores. Esta decisión permitió diagnosticar una nueva dimensión del Derecho de la Publicidad ${ }^{3}$.

Así las cosas, la exigencia de un deber de información al anunciante se introduce por primera vez en el Derecho norteamericano. En efecto, tras la modificación de la Federal Trade Commission Act en 1938, la WheelerLea Act incluye en aquel texto legal un nuevo precepto -el art. 15- que establece que el carácter engañoso de un mensaje depende no sólo de los datos incluidos en el anuncio, sino también de la información omitida cuya importancia deberá valorarse teniendo en cuenta las alegaciones recogidas en la publicidad, así como las consecuencias derivadas de la utilización del producto.

En el ámbito comunitario, sin embargo, la figura del silencio del anunciante no se tipifica expresamente hasta el año 2005, cuando el Parlamento Europeo y el Consejo adoptaron la Directiva sobre prácticas comerciales desleales. En efecto, una de las principales novedades de esta norma, en relación con la Directiva 84/450, es la prohibición -en el art. 7- de las omisiones engañosas. Y decimos que es una novedad porque, a pesar de que la versión inicial del Proyecto de Directiva sobre publicidad engañosa y desleal y el texto posterior modificado regulaban esta deformación publicitaria en su art. 3, la tipificación de esta figura desapareció cuando el Proyecto se convirtió en Directiva.

La laguna de la primera Directiva sobre publicidad engañosa, no impidió que la vis expansiva de la obligación de informar se plasmase en los ordenamientos jurídicos de algunos países europeos, aunque difieren los presupuestos necesarios para que pueda imponerse al anunciante tal obligación ${ }^{4}$. Así, en España se aprobó la LGP. La citada norma contenía en

2 En este sentido, vid. C. FERNÁNDEZ NÓVOA, "La interpretación jurídica de las expresiones publicitarias", en Estudios de Derecho de la Publicidad, Servicios de Publicacións da Universidade de Santiago de Compostela, Santiago de Compostela, 1989, p. 58. Conviene advertir, sin embargo, que la doble finalidad que el último autor citado atribuye a la publicidad ha sido objeto de un animado debate doctrinal. Así, mientras que algunos afirman que los mensajes publicitarios únicamente contienen comunicaciones puramente informativas, otros consideran que albergan manifestaciones esencialmente persuasivas. Las diferentes tesis son recogidas sintéticamente por F. MUNNÉ, "Información social y persuasión social en la publicidad de masas", Pubtec., núm. 38-44 (1976-77), pp. 49-62.

3 C. FERNÁNDEZ NÓVOA, "Actuales tendencias del Derecho de la Publicidad", en Estudios..., op. cit., p. 334.

${ }^{4}$ En efecto, antes de su reconocimiento legal en el Derecho comunitario, la publicidad engañosa por omisión ya era contemplada por las leyes nacionales de algunos países del entorno. El primer texto europeo en ocuparse de su regulación fue la Ley sueca sobre 
el art. 4 una referencia expresa al silencio del anunciante. A tenor de su párrafo segundo "es asimismo engañosa la publicidad que silencie datos fundamentales de los bienes, actividades o servicios cuando dicha omisión induzca a error de los destinatarios"

Tres años más tarde veía la luz la Ley 3/1991, de 10 de enero, de Competencia Desleal (LCD). Aunque con una técnica legislativa menos depurada, su art. 7 calificaba como desleal la falta de información. Según disponía este precepto, "se considera desleal la utilización o difusión de indicaciones incorrectas o falsas, la omisión de las verdaderas y cualquier otro tipo de práctica que, por las circunstancias en que tenga lugar, sea susceptible de inducir a error a las personas a las que se dirige o alcanza, sobre la naturaleza, modo de fabricación o distribución, características, aptitud en el empleo, calidad y cantidad de los productos y, en general, sobre las ventajas realmente ofrecidas" ${ }^{\prime 6}$.

Finalmente, tras las modificaciones introducidas en la LCD por la Ley 29/2009, de 30 de diciembre, el actual art. 7 señala que "se considera desleal la omisión u ocultación de la información necesaria para que el destinatario adopte o pueda adoptar una decisión relativa a su comportamiento económico con el debido conocimiento de causa. Es también desleal si la información que se ofrece es poco clara, ininteligible, ambigua, no se ofrece en el momento adecuado, o no se da a conocer el propósito comercial de esa práctica, cuando no resulte evidente por el contexto. 2. Para la determinación del carácter engañoso de los actos a que se refiere el apartado anterior, se atenderá al contexto fáctico en que se producen, teniendo en cuenta todas sus características y circunstancias y las limitaciones del medio de comunicación utilizado. Cuando el medio de comunicación utilizado imponga limitaciones de espacio o de tiempo, para valorar la existencia de una omisión de información se tendrán en cuenta estas limitaciones y todas las medidas adoptadas por el empresario o profesional para transmitir la información necesaria por otros medios".

Junto a estas normas que disciplinan el engaño por omisión, el ordenamiento jurídico contempla un elenco de leyes especiales que establecen obligaciones específicas de información relacionados con las prácticas comerciales desleales, incluida la publicidad, en materia de medicamentos, etiquetado, presentación y publicidad de los productos, indicación de precios, aprovechamiento por turno de bienes inmuebles, crédito al consumo, comercialización a distancia de servicios financieros

prácticas del mercado de 1975, cuyo art. 3 reglamentaba esta figura mediante una cláusula general que obligaba al anunciante a suministrar la información que pudiese revestir cierta entidad para los consumidores.

Más recientemente, el art. 4 de la UWG de 2004 estableció que "para determinar si la omisión de un hecho es engañosa, debe tenerse en cuenta, en especial, su importancia para la adopción de la decisión de celebrar el contrato según la opinión del círculo de destinatarios, así como la idoneidad de la omisión para influir en la decisión". Sobre este texto legal, vid. R. GARCÍA PÉREZ, "La nueva Ley alemana contra la competencia desleal", RDM, núm. 258, octubre-diciembre (2005), pp. 1659-1673.

5 Énfasis propio.

6 Énfasis propio. 
destinados a los consumidores y usuarios, comercio electrónico, inversión colectiva en valores mobiliarios, normas de conducta en materia de servicios de inversión, oferta pública o admisión de cotización de valores y seguros. Con respecto a este tipo de menciones, su inadvertencia en un anuncio constituirá automáticamente una omisión engañosa en virtud de lo dispuesto en el párrafo segundo del apartado 4 del art. 19 del Texto Refundido de la Ley General para la Defensa de los consumidores y usuarios (TRLGDCU). En efecto, tal y como señala este precepto, "el incumplimiento de las disposiciones a que hace referencia este apartado será considerado en todo caso práctica desleal por engañosa, en iguales términos a lo dispuesto en el artículo 19.2 de la Ley 3/1991, de 10 de enero, de Competencia Desleal en relación con las prácticas engañosas reguladas en los artículos 20 a 27 de dicha ley".

En atención a todo lo hasta aquí expuesto, se puede adivinar que en el moderno Derecho de la Publicidad hay una tendencia a reforzar la dimensión informativa de la publicidad sobre la función persuasiva.

\section{PUBLICIDAD COMERCIAL Y LIBERTAD DE EXPRESIÓN \\ 2.1. Introducción}

Como puede observarse, tanto en el Derecho norteamericano como en la legislación europea y española conviven una serie de normas que, o bien prohíben el engaño por omisión, o bien exigen que la publicidad proporcione unos datos mínimos.

En este estado de la cuestión, cabe preguntarse si tales normas son compatibles con el derecho a la libertad de expresión. Para dar cumplida respuesta a esta pregunta debemos analizar, en primer lugar, si este derecho se extiende a la publicidad comercial. Sólo cuando el resultado del análisis fuese positivo, podrá determinarse, en segundo lugar, hasta qué punto la exigencia de un deber de información al anunciante podría suponer una injerencia injustificada en el citado derecho.

\subsection{El amparo constitucional de la publicidad comercial en el Derecho norteamericano}

La Primera Enmienda a la Constitución americana prohíbe la adopción por el Congreso de una ley que coarte la libertad de expresión. A la hora de determinar si dicha prohibición resulta aplicable a la publicidad comercial $^{7}$, habrá que remontarse al año 1942, fecha en la que el Tribunal Supremo resolvió el caso "Valentine v. Chrestensen"8. En efecto, tal y

\footnotetext{
7 Sobre el tema, vid. R. PETTY, "Advertising and the First Amendment: A Practical Test for Distinguishing Commercial Speech from Fully Protected Speech", ALA, vol. XVII, enero-junio (1994), pp. 170-176. En la doctrina española, C. FERNÁNDEZ NÓVOA, "Actuales tendencias...", op. cit., pp. 327-332; A. TATO PLAZA, "Publicidad comercial y libertad de expresión en la jurisprudencia norteamericana", ADI 14 (1991-92), pp. 169196; ibídem, "Publicidad comercial y libertad de expresión en la jurisprudencia norteamericana: nuevos desarrollos", ADI 15 (1993), pp. 843-848; A. RUBÍ I PUIG, Publicidad y libertad de expresión, Thomsom-Civitas, Cizur Menor, 2008, pp. 93-117.

${ }^{8}$ Supreme Court of United States, sentencia de 13 de abril de 1942, caso "Valentine v. Chrestensen". El texto de esta sentencia se reproduce en US, pp. 52 y ss.
} 
como subraya PLATT, el origen de la commercial speech doctrine se inicia cuando el Alto Tribunal, en su sentencia de 13 de abril de 1942, "comenzó a dibujar la distinción constitucional entre la regulabilidad del mensaje comercial y la del mensaje no comercial" ${ }^{\prime 9}$.

En este asunto, el Sr. Chrestensen, un ciudadano de Florida, había adquirido un antiguo submarino de la Armada que se exponía por distintos puertos norteamericanos con fines lucrativos. Al llegar a New York, publicó un folleto anunciando la exhibición. En su intento de distribuirlo por las calles de la ciudad, fue advertido de que el $\S 318$ del Código Sanitario prohibía la distribución de publicidad comercial y de negocios en las vías públicas, aunque sí permitía difundir panfletos que contuviesen una protesta pública. Por este motivo, el propietario decidió incluir en el reverso del folleto una queja dirigida a las autoridades sobre su gestión de los embarcaderos. Pese a la modificación operada, la policía confiscó el folleto y el empresario decidió entonces acudir a los Tribunales alegando que se había vulnerado su derecho a la libertad de expresión.

Cuando el caso llegó al Supremo, éste confirmó el carácter publicitario del documento, al tiempo que consideró la inserción de la protesta pública como un mero intento de evadir la prohibición sentada por la ordenanza municipal. Por último, concluyó que la publicidad comercial constituía una de las formas de discurso no protegidas por la Primera Enmienda.

Sin embargo, la postura que niega la posibilidad de proteger los mensajes publicitarios al amparo del derecho a la libertad de expresión respaldada durante décadas por la jurisprudencia- entró en un proceso que en la doctrina americana se conoce como erosión de la commercial speech doctrine. Dentro de esta nueva etapa constituye un hito destacado la sentencia de 24 de mayo de 1976, que resolvió el caso "Virginia State Board of Farmacy"10. En ella el Supremo declaró inconstitucional un precepto de una Ley del Estado de Virginia que prohibía a los farmacéuticos difundir mensajes publicitarios indicando los precios de los medicamentos que requieren prescripción médica. En apoyo de su decisión, el Tribunal ofrece un análisis de los beneficios de la publicidad comercial desde la perspectiva del anunciante, de los consumidores y de la sociedad en general. Partiendo de dicho análisis, justifica la protección constitucional del discurso comercial con las siguientes palabras: "aunque la publicidad puede parecer en ocasiones excesiva y de mal gusto, divulga información respecto de quién fabrica y vende un determinado producto, por qué razón y a qué precio. En la medida en que conservemos un sistema económico de libre empresa, la colocación de nuestros recursos se hará principalmente a través de decisiones económicas privadas. Es un asunto de interés público que esas decisiones sean inteligentes y se efectúen con apoyo en una buena información. Para lograr este fin, es indispensable la libre circulación de información comercial".

\footnotetext{
${ }^{9}$ Citado a través de A. TATO PLAZA, "Publicidad comercial...", op. cit., p. 170.

10 Supreme Court of United States, sentencia de 24 de mayo de 1976, caso "Virginia State Board of Pharmacy et al. v. Virginia Citizens Consumer Council Inc., et al.", Trade Cas., 1976-1, pp. 69045- 69061.
} 
Así pues, tras abandonar la tesis tradicional, fueron muchas las sentencias posteriores -entre otras, "Central Hudson Gas and Electric Corp. v. Public Services Commission of New York" y "Board of Trustees of the State University of New York et al. v. Todd Fox et al."- que siguiendo la postura establecida por el Tribunal Supremo en su sentencia de 24 de mayo de 1976, la fueron matizando hasta configurar una doctrina que considera que el mensaje comercial continua gozando de la protección de la Primera Enmienda. Al mismo tiempo, reconoce que dicha protección es menor que la que se atribuye a los comentarios directos sobre asuntos de interés público, de forma que podrá ser objeto de ciertas medidas restrictivas. La licitud de tales medidas está condicionada a la concurrencia de los siguientes requisitos: 1) que esté prevista por la ley; 2) que la misma se encamine de forma directa a la consecución del interés protegido; 3) que exista una concordancia razonable entre la medida dictada y el interés que se intenta satisfacer.

\subsection{El amparo constitucional de la publicidad comercial en la jurisprudencia del Tribunal Europeo de Derechos Humanos (TEDH)}

El apartado 1 del art. 10 del Convenio Europeo de Derechos Humanos (CEDH) consagra el derecho a la libertad de expresión en los términos que se exponen a continuación: "toda persona tiene derecho a la libertad de expresión. Este derecho comprende la libertad de opinión y la libertad de comunicar y recibir informaciones e ideas sin que pueda existir injerencia de las autoridades públicas, y sin consideración de fronteras"

En el momento de decidir sobre la aplicación del precepto transcrito a la publicidad comercial ${ }^{11}$, la postura del TEDH difiere de la mantenida en un principio por el Alto Tribunal norteamericano. Sin embargo, las últimas decisiones de aquel órgano se aproximan en cierta medida a la tesis defendida en la actualidad por el Supremo. En este sentido, la sentencia de 24 de febrero de 1994, es la que mejor resume la doctrina del Tribunal europeo sobre la protección de la publicidad por el art. 10.1 del CEDH ${ }^{12}$.

Los hechos que dieron lugar a la citada sentencia fueron los siguientes: el Sr. Pablo Casado Coca, abogado en ejercicio, se trasladó en el año 1979- a Barcelona donde abrió un despacho. Con la finalidad de darse a conocer ante sus potenciales clientes, publicó en diferentes medios de comunicación varios anuncios ofreciendo sus servicios. La Junta de Gobierno del Colegio de Abogados de Barcelona estimó que su conducta vulneraba el art. 31 del Real Decreto 2090/1982, de 24 de julio, que prohibía a los abogados el anuncio o difusión de sus servicios a través de medios publicitarios. Por este motivo, impuso varias sanciones de apercibimiento al Sr. Casado. Los recursos que éste interpuso frente a las

\footnotetext{
${ }^{11}$ Para un análisis de la relación entre la publicidad comercial y la libertad de expresión en la jurisprudencia europea, vid. A. TATO PLAZA, "Derecho privado, publicidad y libertad de expresión en la Europa de los veinticinco miembros", en Estudios de Derecho Mercantil Europeo, Marcial Pons, Madrid, 2005, pp. 105-118 y La publicidad comparativa, Marcial Pons, Madrid, 1996, pp. 108 y ss.

12 TEDH, sentencia de 24 de febrero de 1994, caso "Casado Coca c. España", TEDH $1994 / 1$.
} 
mismas fueron sucesivamente desestimados por la Audiencia Territorial de Barcelona y por el Tribunal Supremo. Fue entonces cuando el Sr. Casado decidió acudir al TEDH, alegando que la sanción impuesta constituía una injerencia en su derecho a la libertad de expresión. El TEDH, por el contrario, sí reconoce que la publicidad puede beneficiarse de la protección conferida por el art. $10 \mathrm{CEDH}$ en tanto en cuanto transmita información útil para la audiencia. Así, de acuerdo con este órgano jurisdiccional, "para el ciudadano, la publicidad constituye un medio para dar a conocer las características de los servicios y los bienes que le son ofrecidos. No obstante, a veces puede ser objeto de restricciones destinadas, especialmente a impedir la competencia desleal y la publicidad falsa o engañosa"13.

\subsection{El amparo constitucional de la publicidad comercial en la jurisprudencia del Tribunal Supremo (TS)}

En el marco del Derecho español, la libertad de expresión se encuadra dentro del Título I de la Constitución Española (CE) rotulado "Derechos y deberes fundamentales". Concretamente, el art. 20 reconoce, entre otros, el derecho "a expresar y difundir libremente los pensamientos, ideas y opiniones mediante la palabra, el escrito, o cualquier otro medio de reproducción", así como el derecho "a comunicar y recibir libremente información veraz por cualquier medio de difusión".

Durante muchos años, nuestro Alto Tribunal negó sistemáticamente que la publicidad estuviese amparada por las normas constitucionales que garantizan el derecho a la libertad de expresión ${ }^{14}$. En la actualidad, en cambio, reconoce abiertamente la posibilidad de adscribir el mensaje publicitario dentro del ámbito de protección del art. 20 CE. Para ilustrar esta afirmación, podemos traer a colación la sentencia de 15 de enero de $2010^{15}$. La citada sentencia tiene su origen en una demanda que interpuso la Asociación de Usuarios de la Comunicación contra un anuncio difundido en televisión para promocionar el vehículo "Mitsubishi Galant". En dicho anuncio, se observa a un hombre que camina por un garaje subterráneo mientras va aproximándose a un vehículo situado bajo un cartel en el que se puede leer: "Director General". Al mismo tiempo, una voz en off dice: "¿Has visto el coche nuevo del Director General?, iEs impresionante el coche nuevo del Director General!, iCómo me gustaría probar el coche nuevo del Director General!". Al situarse a la altura del coche, deposita su maletín, saca del bolsillo un elemento punzante y pincha dos de sus

\footnotetext{
13 A pesar de estas afirmaciones, el TEDH desestimó el recurso interpuesto por el Sr. Casado al considerar que la sanción impuesta era necesaria en una sociedad democrática para la protección de los derechos ajenos. Sobre esta cuestión, vid. A. TATO PLAZA, "Publicidad comercial y libertad de expresión en Europa", La Ley, núm. 3 (1994), pp. 988-1000.

${ }^{14}$ A título de ejemplo, puede consultarse la sentencia de 23 de septiembre de 1988 , RJ $1988 / 6821$.

15 TS, sentencia de 15 de enero de 2010, RJ 2010/415. Para un análisis de la misma, vid. C. GIL MEMBRADO, "El anuncio publicitario como ejercicio del derecho a la libre expresión. A propósito del caso Mitsubishi", InDret, núm. 2, (2011), pp.1-25.
} 
ruedas, mientras se escucha la siguiente afirmación: "Regla número 1 de los negocios: el Director General nunca debe comprarse un coche mejor que el del Presidente". A continuación, se advierte como otro vehículo, aparcado próximo a un rótulo en el que figura el vocablo "Presidente", se pone en marcha y sale del aparcamiento subterráneo.

La Asociación de Usuarios de la Comunicación declaró que este anuncio constituía un supuesto de publicidad ilícita en el sentido del art. 3, letras a) y e), de la LGP de 1988 y, en consecuencia, demandó a la mercantil "Mitsubishi Motors Corporation Automóviles España, S.A.". El Juzgado de Primera Instancia núm. 34 de Madrid, en su sentencia de 16 de julio de 2002, estimó la demanda y ordenó el cese de la publicidad. Frente a esta sentencia, interpuso recurso de apelación la demandada alegando -entre otros motivos - que al prohibir la difusión del mensaje se había vulnerado su derecho a la libertad de expresión. La Audiencia dictó sentencia el 10 de diciembre de 2004. En ella coincidió con el análisis realizado por el juez a quo, considerando que el anuncio infringía el art. 3 LGP al presentar "patrones compulsivos de conductas relativas a la tenencia 0 adquisición de bienes y productos que resultan ser merecedores de reproche penal". A la vista del fallo de esta sentencia, la empresa "Mitsubishi" recurrió en casación ante Tribunal Supremo invocando nuevamente la violación del art. 20 CE.

En relación con esta cuestión, el Alto Tribunal afirmó que no cabe "negar a los mensajes comerciales acceso al ámbito de regulación cuyo núcleo representa el artículo 20 de la Constitución Española". Si bien, a continuación, puntualizó que el reconocimiento de protección constitucional a la publicidad no impide la adopción de ciertas medidas restrictivas, cuya licitud dependerá del cumplimiento de tres requisitos. Así, "la restricción debe estar justificada, ya por imponerla la regulación constitucional del propio derecho o a la concurrencia con él de otros igualmente fundamentales; ya por perseguir fines legítimos según el ordenamiento constitucional, entre otros, los configurados como derechos y deberes de los ciudadanos o como principios rectores de la política económica o por el legislador ordinario para el logro de objetivos de interés general. La restricción ha de resultar, además, idónea, en el sentido de adecuada para contribuir a la obtención del fin que la legitime. Finalmente, deberá ser proporcionada desde el punto de vista del contenido esencial del derecho restringido, cuyo necesario respeto -art. 53.1 de la Constitución- opera, al fin, como límite de los propios límites".

Al aplicar los requisitos apuntados al anuncio que nos ocupa, el Tribunal Supremo concluyó que "el mensaje publicitario prohibido exteriorizaba y hacía llegar a sus destinatarios una información realmente útil, mediante la proyección de una escena con algún grado de creatividad, cuyo núcleo lo constituía una reacción provocada por la envidia $y$, en sí, sancionada penalmente. Sin embargo, con razón sostiene la recurrente que la naturaleza ridícula de la situación, su contenido jocoso, el contraste y la incongruencia entre la aparente seriedad del personaje principal del anuncio y su absurda reacción, convierten al mismo en inocuo e intrascendente desde el punto de vista de los bienes 
que el Tribunal de apelación se decidió a proteger".

En vista de tales argumentos, el Supremo constató "la realidad de una injerencia innecesaria en defensa de un bien -la dignidad de la personaque no había sido lesionado ni amenazado".

\section{OMISIONES ENGAÑOSAS Y LIBERTAD DE EXPRESIÓN}

Acabamos de comprobar como en el plano jurisprudencial existe unanimidad en considerar que la publicidad comercial no es extraña al ámbito de protección conferido por la libertad de expresión. No obstante, a juicio del Tribunal Constitucional $(\mathrm{TC})^{16}$, ningún derecho es ilimitado y, por consiguiente, tampoco lo es el derecho a la libertad de expresión. Con carácter general, éste se encuentra sometido a las restricciones contenidas en el art. 10.2 de la CEDH, a cuyo tenor las injerencias en el ejercicio de tal derecho deben estar previstas por la ley y constituir medidas necesarias, en una sociedad democrática, para garantizar la seguridad nacional, la integridad territorial o la seguridad pública, la defensa del orden y la prevención del delito, la protección de la salud o de la moral, la protección de la reputación o de los derechos de terceros; para impedir la divulgación de informaciones confidenciales; 0 , para asegurar la autoridad y la imparcialidad del poder judicial.

Llegados a este punto, procede analizar si en materia de competencia desleal las normas que prohíben el engaño por omisión y las que exigen que la publicidad tenga un mínimo contenido informativo respetan las medidas apuntadas, esto es: si están previstas por la ley, si se encaminan a la consecución de alguno de los objetivos que enumera el último precepto citado y si constituyen una medida necesaria en una sociedad democrática.

Pero antes de responder a esta cuestión, parece conveniente examinar siquiera sucintamente cada uno de estos requisitos de licitud ${ }^{17}$. Así, en primer lugar, la medida restrictiva tiene que estar prevista en norma con rango de ley. A su vez, dicha norma debe ser accesible y precisa. Con la formulación de estos requisitos, el TEDH pretende que el ciudadano pueda disponer de patrones suficientes para adecuar a ella su conducta y prever las posibles consecuencias de una determinada acción ${ }^{18}$.

En segundo lugar, la medida estará encaminada a proteger alguno de los intereses que, de forma exhaustiva, enumera el art. 10.2 CEDH -en concreto, seguridad nacional, integridad territorial, seguridad pública, prevención del desorden o del crimen, protección de la salud o de la moral, protección de la reputación o de los derechos ajenos, impedir la divulgación de informaciones confidenciales, o garantizar la autoridad e imparcialidad del poder judicial-.

\footnotetext{
${ }^{16}$ Vid., por ejemplo, las sentencias del TC de 8 de abril de 1981 y 26 de noviembre de 1990.

${ }^{17}$ Para un análisis más detallado, vid. A. TATO PLAZA, La publicidad..., op cit., pp. 113 y SS.

${ }^{18}$ TEDH, sentencia de 26 de abril de 1979, caso "Sunday Times c. Reino Unido", TEDH $1979 / 1$.
} 
Por último, la medida tiene que ser necesaria en una sociedad democrática. La concurrencia de este requisito será comprobada por los Estados contratantes, que gozan de un margen de apreciación limitado y diferente en función del objetivo legítimo perseguido por la medida restrictiva y de la materia. Así, en el marco del Derecho contra la Competencia Desleal y la Publicidad, "la tarea del Tribunal se limita a investigar si, en el caso concreto, las medidas adoptadas a nivel nacional se justifican en su origen y son proporcionadas" ${ }^{19}$.

Hechas estas puntualizaciones, únicamente nos queda por comprobar si las omisiones engañosas, de un lado, y las leyes que imponen obligaciones específicas de información, de otro lado, podrían superar el test de constitucionalidad.

\subsection{Omisiones engañosas}

En relación con las omisiones engañosas, ya tuvimos ocasión de comprobar como en los ordenamientos jurídicos de los diferentes países existen normas que prohíben expresamente esta figura. Así pues, no pueden surgir dudas sobre el cumplimiento del primer requisito.

Por lo que concierne al segundo, conviene advertir que si uno de los presupuestos de licitud de toda medida restrictiva de la libertad de expresión es la consecución de un fin legítimo $y$, dentro de ellos, la "protección de los derechos ajenos" -entre los que se incluyen los intereses de los consumidores ${ }^{20}$ - es el que justificaría la tipificación del engaño por omisión, en el supuesto analizado tales intereses constituyen uno de los pilares sobre los que se asienta tradicionalmente la prohibición de la publicidad falaz.

Por último, con independencia de la cuestión de precisar qué medidas son "necesarias" y cuáles no, hay que señalar que el hecho de que el legislador no califique como ilícita per se la omisión de información, sino únicamente el silencio de aquellos datos que son aptos para inducir a error al consumidor o para generar en éste falsas expectativas, revela inequívocamente que se trata de una medida proporcionada al fin perseguido (proteger los intereses económicos de los consumidores).

Dicho esto, no parecen necesarios mayores argumentos para concluir que las leyes que prohíben omitir datos esenciales -o, utilizando la terminología del legislador español, "necesarios"- de los productos o servicios anunciados, respetan las medidas apuntadas y, por consiguiente, deben considerarse una injerencia lícita en el derecho a la libertad de expresión.

\subsection{Leyes que imponen obligaciones específicas de información}

Aunque resulte paradójico, en el supuesto de normas que contienen una serie de menciones que deben figurar en la publicidad, la conclusión a la que se llega es radicalmente opuesta. En efecto, aunque de forma

\footnotetext{
${ }^{19}$ Vid. Caso "Casado Coca c. España", p. 14.

20 En este sentido, A. TATO PLAZA, La publicidad comparativa, Marcial Pons, Madrid, 1996, p. 118.
} 
coincidente con las omisiones engañosas, la imposición de un deber positivo de informar está prevista en una pléyade de leyes especiales y constituye además una medida encaminada a garantizar la protección de los derechos ajenos; difieren en el tercer requisito que -recordemosexige que la medida restrictiva del derecho a la libertad de expresión sea necesaria. A este respecto, el TEDH sostiene que para constatar su existencia deberá averiguar si la medida es proporcionada al fin legítimo perseguido, teniendo en cuenta los distintos intereses implicados en cada caso. Concretamente, en materia de competencia desleal, se debe priorizar el interés económico de los consumidores, que en este ámbito se traduce en la adopción de decisiones relativas a su comportamiento económico con el debido conocimiento de causa teniendo en cuenta la información proporcionada. En consecuencia quedan fuera del ámbito de protección otros intereses, tales como la salud y la seguridad, en la medida en que no comprometan también sus intereses económicos.

Pues bien, dado que como vimos con anterioridad, el art. 19.4 TRLGDCU contempla un amplio abanico de leyes que imponen obligaciones específicas de información en relación con las prácticas comerciales desleales, a la hora de valorar la concurrencia de este último requisito vamos a realizar una valoración de conjunto distinguiendo para ello dos tipos de normas. Por un lado, aquellas que exigen revelar ciertas informaciones cuya omisión implicará un reproche automático de deslealtad $^{21}$; sin embargo, por su escasa entidad, difícilmente pueden provocar el error del consumidor ni, por consiguiente, distorsionar su comportamiento económico. En este sentido, podemos citar el art. 78.2, apartado c), de la Ley 29/2006, de 26 de julio, de garantías y uso racional de los medicamentos y productos sanitarios, que requiere que en la publicidad de este tipo de productos se incluya una invitación expresa y claramente visible a leer detenidamente las instrucciones que figuren en el prospecto o en el embalaje externo. Sin embargo, resulta difícil pensar que la falta de esta información en un anuncio pueda llevar al consumidor a adoptar una decisión distinta de la que habría tomado de haber conocido dicha información. En consecuencia, las leyes que exigen al anunciante incluir en sus mensajes publicitarios datos de poca importancia para la decisión del consumidor, constituirían una intromisión injustificada en el derecho a la libertad de expresión por no ser proporcionadas al fin perseguido que, como ya avanzamos, consiste en proteger los derechos económicos de los consumidores evitando que estos adopten una decisión sobre su comportamiento que, de haber conocido esa información, no habrían tomado.

Por otro lado, encontramos normas en las que se exige la inclusión de ciertas menciones cuya omisión sí podría generar falsas expectativas en el consumidor. Por citar un ejemplo, el art. 9 de la Ley 16/2011, de 24 de junio, de contratos de crédito al consumo, regula de forma detallada la información que deberá figurar en la publicidad y en las comunicaciones

\footnotetext{
${ }^{21}$ Así lo afirma expresamente el párrafo 2 del art. 19.4 TRLGDCU, al señalar que "será considerado en todo caso práctica desleal por engañosa".
} 
comerciales en las que se ofrezca un crédito, siempre que se indique el tipo de interés. Tal información se refiere -entre otros- al tipo deudor (fijo o variable), el importe total del crédito y la tasa anual equivalente. En este supuesto, la injerencia en el derecho a la libertad de expresión estaría justificada, pues, además de transmitir información útil a los consumidores -en la medida en que les permite conocer el coste del crédito y entablar un análisis comparativo con otras ofertas similares-, la obligación en la indicación de aquellos extremos se limita a los casos en los que se incluya el tipo de interés o cualquier otra cifra relacionada con el precio del crédito. De esta forma, el destinatario del mensaje podrá comprender las repercusiones del contrato de crédito en su situación económica y adoptar una decisión sobre dicho contrato con el debido conocimiento de causa ${ }^{22}$.

\section{BIBLIOGRAFÍA}

J. ADLER, "Compelled commercial speech and consumer right to know", Arizona Law Review, núm. 58, 421 (2016), pp. 422-476.

C. FERNÁNDEZ NÓVOA, "La interpretación jurídica de las expresiones publicitarias", en Estudios de Derecho de la Publicidad, Servicio de Publicacións da Universidade de Santiago de Compostela, Santiago de Compostela, 1989, pp. 57-92.

C. FERNÁNDEZ NÓVOA, "Actuales tendencias del Derecho de la Publicidad", en Estudios de Derecho de la Publicidad, Servicio de Publicacións da Universidade de Santiago de Compostela, Santiago de Compostela, 1989, pp. 327-338.

E. GALÁN CORONA, "Análisis de la jurisprudencia publicitaria (parte I)", Autocontrol, núm. 145, octubre (2009), pp. 10-14.

R. GARCÍA PÉREZ, "La nueva Ley alemana contra la competencia desleal", RDM, núm. 258, octubre-diciciembre (2005), pp. 1659-1673.

C. GIL MEMBRADO, "El anuncio publicitario como ejercicio del derecho a la libre expresión. A propósito del caso Mitsubishi", InDret, núm. 2, (2011), pp.1-25.

F. MUNNE, "Información social y persuasión social en la publicidad de masas", Pubtec., núm. 38-44 (1976-77), pp. 49-62.

R. PETTY, "Advertising and the First Amendment: A Practical Test for Distinguishing Commercial Speech from Fully Protected Speech", ALA, vol. XVII, enero-junio (1994), pp. 170-176.

A. RUBÍ I PUIG, Publicidad y libertad de expresión, Thomsom-Civitas, Cizur Menor, 2008, 477 pp.

A. TATO PLAZA, "Publicidad comercial y libertad de expresión en la jurisprudencia norteamericana: nuevos desarrollos", ADI 15 (1993), pp. 843-848.

A. TATO PLAZA, "Publicidad comercial y libertad de expresión en Europa", La Ley, núm. 3 (1994), pp. 988-1000.

\footnotetext{
${ }^{22}$ Nótese que la contratación de un bien o servicio, así como la manera y condiciones de contratarlo es una de las decisiones que se incluyen dentro de la definición de comportamiento económico. Vid., en este sentido, el art. 4.1 de la LCD.
} 
A. TATO PLAZA, La publicidad comparativa, Marcial Pons, Madrid, 1996, $335 \mathrm{pp}$.

A. TATO PLAZA, "La publicidad ilícita en la jurisprudencia y en la doctrina del Jurado de la Publicidad, Autocontrol, núm. 27, enero (1999), pp. 129.

A. TATO PLAZA, "Derecho privado, publicidad y libertad de expresión en la Europa de los veinticinco miembros", en PÉREZ CARILLO, Elena Fátima, (coord.), Estudios de Derecho Mercantil Europeo, Marcial Pons, Madrid, 2005, pp. 105-118. 